\title{
Energy Balance Design and Analysis of Long-flight-time Solar Powered UAV
}

\author{
Zhang Qinling, Huang Jian \\ Research Institute of Unmanned Aerial Vehicle \\ Beijing University of Aeronautics and Astronautics \\ Beijing 100191,China \\ 13511019075@139.com, huangjian53@263.net
}

\author{
Wen Feifei \\ School of Automation Science and Electrical Engineering \\ Beijing University of Aeronautics and Astronautics \\ Beijing 100191,China \\ wff_8@sina.com
}

\begin{abstract}
Characteristics and technical difficulties of longflight-time solar powered UAV airborne power and energy storage system was studied, and a general design method based on energy balance relation and aerodynamic parameters was proposed. The relation formula between key parameters such as solar cell area and energy system weight ratio and aircraft platform aerodynamic parameters, battery performance and battery energy density was derived. Then the long-flight-time solar powered UAV energy system scheme was calculated with domestic mature technical parameters. This method can effectively simplify the calculation process and provide a reference for the overall design of the long-flight-time solar powered UAV platform.
\end{abstract} Battery

Keywords-solar; Unmanned Air Vehicl; Energy Balance;

\section{INTRODUCTION}

Solar powered UAV uses solar radiant energy as promoting energy. The plane should has larger body surface, high flying height, high capacity of the energy system and efficient propulsion system in order to gain enough energy as the energy density of is small. Therefore the long-flight-time solar powered UAV belongs to the upper large UAVs.

Solar powered UAV airborne energy system includes primary power supply(solar cell) and secondary power supply(storage battery), as shown in Fig. 1. The UAV realizes long-time-flight by energy self-supply. During the day, the electricity transformed from radiant energy absorbed by solar powered UAV is used to maintain propulsion system, avionics system and mission payload operating effectively. Besides, the surplus electricity is used for energy storage by airborne secondary power supply so that it can keep the UAV operating effectively[1]. Therefore, as long as

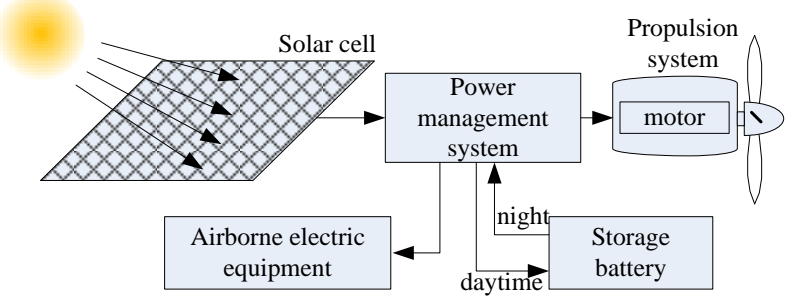

Figure 1. Structure Diagram of Long-flight-time Solar Powered UAV Energy System the energy storage is greater than the night demand, the solar battery can guarantee infinite long navigation theoretically.

\section{KEY TECHNICAL DIFFICULTIES}

Solar cell technology has been widely used in satellite and spacecraft, but the application in UAV has been constrained for physical properties (environment adaptability, reliability, radiation, corrosion), structure design, manufacturing process, manufacturing costs, spectral response range, conversion efficiency and energy storage and so on[2-3]:

1) Satellite solar panels do not need to consider air resistance, while UAV solar cell must be glued to the wing body surface to bearing aerodynamic load.

2) The atmosphere sunshine energy is limited, so there must have enough energy storage capacity to meet the night power needs.

3) Different latitude, longitude and season have different influence on solar radiation energy conversion.

So the main composition of long-flight-time solar powered UAV takeoff weight is solar cell and secondary power. In several typical solar powered UAV, the weight of the above two parts is more than $40 \%$ of takeoff gross weight. At present, the monocrystalline silicon or polycrystalline silicon solar cells, lithium battery and fuel cell are the main choice of long-flight-time solar powered UAV. Looking from mature products, the transformation efficiency of monocrystalline silicon or polycrystalline silicon solar cell can reach $15-20 \%$. The energy density of Li-lon can reach $150-250 \mathrm{Wh} / \mathrm{kg}$, and that of $\mathrm{Li}-\mathrm{S}$ can reach over $400 \mathrm{Wh} / \mathrm{kg}[4-$ 7].

In general, the maximum solar energy density under the vertical irradiation of summer noon is only $1000 \mathrm{~W} / \mathrm{m} 2$, and in winter is only about a quarter of that in summer[8]. Considering the need to consume daytime energy storage at night, the wing area of $1 \mathrm{~m} 2$ provide about an average of $60 \mathrm{~W}$ electric power day and night. And the propulsion and airborne electric equipment of UAV platform need a few kilowatts of electricity, therefore the area of solar cell has to reach hundreds of square meters. Even so, solar cell provides limited weight and energy to the task devices and asks for a high demand for task devices. So solar cells are generally not suitable for UAV with high-power consumption task devices. 
Therefore, how to optimize the design parameters of airborne power generation and energy storage system, and effectively extend flight time and voyage through energy balance are the key to the design of long-flight-time solar powered UAV.

\section{DESIGN AND ANALYSIS OF ENERGy BALANCE}

\section{A. Energy Relation of Solar Powered UAV}

Because the energy is mainly provided for electric propulsion system, the energy balance relation of long-flighttime solar powered UAV can be expressed by (1) when power consumption of airborne electric equipment is ignored

$$
P_{s} / P_{t} \geq 24 \mathrm{~h}
$$

Where $P_{s}$ is the whole solar energy obtained a day and a night, and $P_{t}$ is the aircraft thrust power. Energy balance relation of solar powered UAV is shown in Fig. 2 [9-10].

\section{B. Energy Balance and Structure}

The thrust power needed by full-aircraft during flight is

$$
P=\frac{Q_{j} \times v \times g}{k \times \eta_{m} \times \eta_{B}}
$$

Where $Q_{j}$ is the total weight of UAV, $v$ is flying speed, $g$ is acceleration of gravity, $k$ is lift-drag ratio, $\eta_{m}$ is motor efficiency, $\eta_{B}$ is propeller efficiency.

Supposing $P_{b}$ is electric power of all airborne equipment and $\mathrm{k}_{\mathrm{b}}=P_{b} / P$, the energy needed for $t$ hours of night flying is

$$
W_{b}=P\left(1+k_{b}\right) \times t
$$

Therefore the storage battery weight $Q_{b}$ is

$$
Q_{b}=W_{b} / q
$$

Where $q$ is the energy destiny of storage battery.

In daytime the whole energy which solar cell need to provide is

$$
\begin{aligned}
& W s=\frac{W_{b}}{\eta_{c}}+P\left(1+k_{b}\right) \times(24-t) \\
& =\frac{P \times\left(1+k_{b}\right) \times t}{\eta_{c}}+P\left(1+k_{b}\right) \times(24-t) \\
& =P\left(1+k_{b}\right)\left(\frac{t}{\eta_{c}}+24-t\right)
\end{aligned}
$$

Where $\eta_{c}$ is battery charge and discharge efficiency.

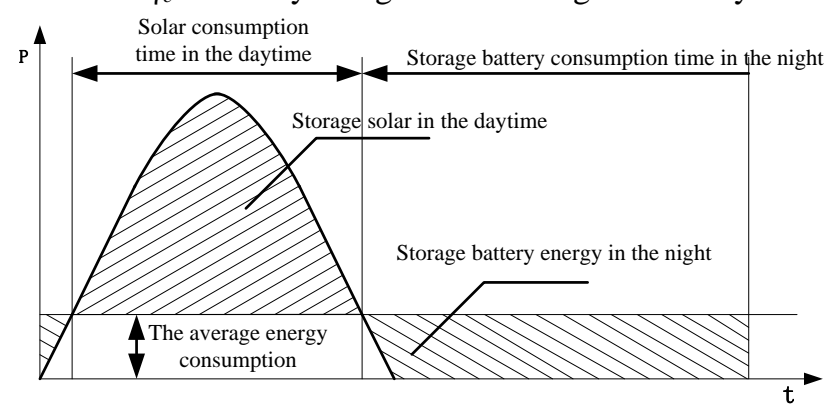

Figure 2. Energy Balance Relation of Solar Cell
This paper assumes that the solar energy changes according to the sine rule with time, and therefore determines the area of the solar cell

$$
S_{s}=W_{s} \times \frac{\pi}{p_{s} \times \eta_{s} \times(24-t)}
$$

Where $P_{s}$ is solar energy density, $\eta_{s}$ is solar cell efficiency.

In the general design method of long-flight-time solar powered UAV, the storage battery weight and solar cell area can be determined as long as UAV gross weight, flight speed, lift-drag ratio and motor efficiency, propeller efficiency and electric power of all airborne equipment are determined.

According to reasoning of fuel energy plane, weight proportion of every part of solar powered UAV can also be drawn.

The storage battery weight $Q_{b}$ to whole machine weight ratio is

$$
Q_{b} / Q_{j}=\left(\frac{Q_{j} \times v \times g}{k \times \eta_{m} \times \eta_{B} \times q}\right) \times t \times\left(1+k_{b}\right) / Q_{j}=\frac{v \times g \times\left(1+k_{b}\right)}{k \times \eta_{m} \times \eta_{B} \times q} \times t
$$

The solar cell weight $Q_{s}$ to whole machine weight ratio is

$$
\begin{aligned}
& Q_{s} / Q_{j}=S_{s} \times q_{s} / Q_{j} \\
& =W_{s} \times \frac{\pi \times q_{s}}{p_{s} \times \eta_{s} \times(24-t)} / Q_{j} \\
& =\frac{p \times\left(\frac{t}{\eta_{c}}+24-t\right) \times \pi \times q_{s}}{p_{s} \times \eta_{s} \times(24-t) \times Q_{j}} \times\left(1+k_{b}\right) \\
& =\frac{v \times g \times\left(\frac{t}{\eta_{c}}+24-t\right) \times \pi \times q_{s}}{k \times \eta_{m} \times \eta_{\mathbf{B}} \times p_{s} \times \eta_{s} \times(24-t)} \times\left(1+k_{b}\right)
\end{aligned}
$$

Assuming the weight per unit area of the solar cell is $q_{s}$, then the weight of storage battery plus solar cell to whole machine weight ratio is

$$
\begin{aligned}
& \left(Q_{b}+Q_{s}\right) / Q_{j} \\
& =\frac{v \times g \times\left(1+k_{b}\right)}{k \times \eta_{m} \times \eta_{B} \times q} \times t+\frac{v \times g \times\left(\frac{t}{\eta_{c}}+24-t\right) \times \pi \times q_{s}}{k \times \eta_{m} \times \eta_{\mathbf{B}} \times p_{s} \times \eta_{s} \times(24-t)} \times\left(1+k_{b}\right) \\
& =\frac{v \times g \times\left(1+k_{b}\right)}{k \times \eta_{m} \times \eta_{B}} \times\left\{\frac{t}{q}+\frac{\left(\frac{t}{\eta_{c}}+24-t\right) \times \pi \times q_{s}}{p_{s} \times \eta_{s} \times(24-t)}\right\}
\end{aligned}
$$

From (9) it can be seen that the ratio is related to flight parameters, battery performance, battery energy density and ratio of all airborne equipment electric power to thrust power. Therefore, if the aircraft platform airborne equipment needs to increase the capacity of electricity, there are three ways: 1) increase aircraft thrust power; 2) improve battery performance; 3) reduce the weight ratio of other parts.

\section{Method Design and Analysis}

The general design block diagram of solar powered UAV based on the above method is shown in Fig. 3 . 


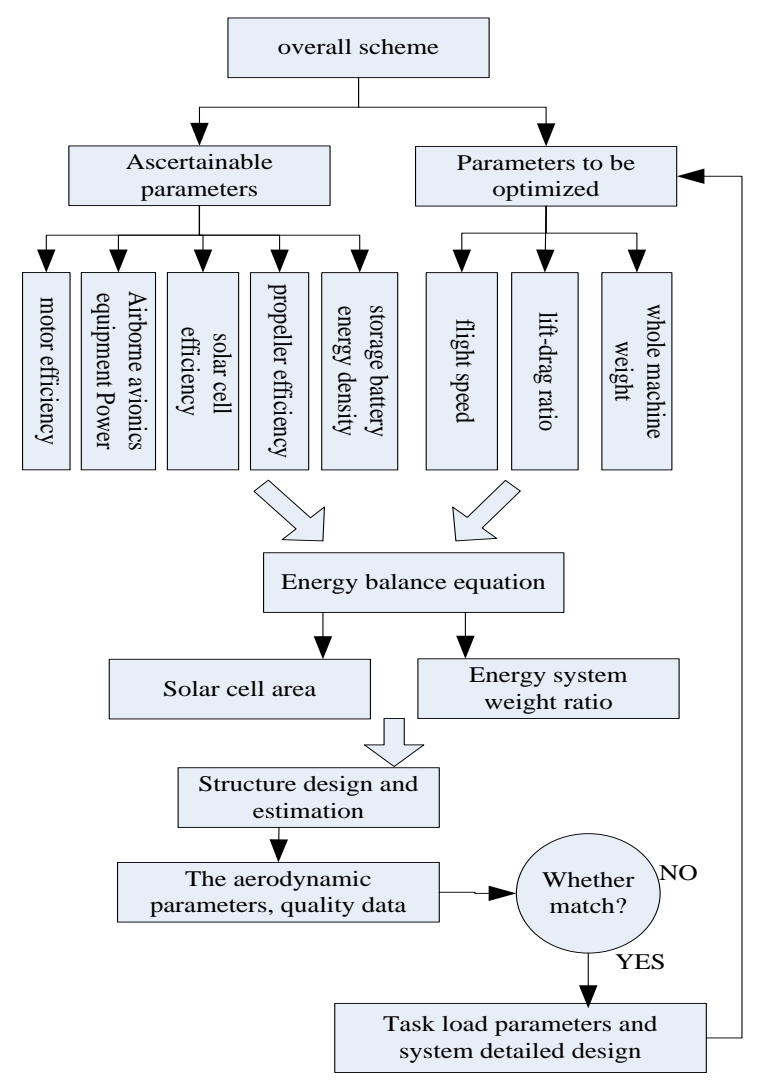

Figure 3. The general design block diagram of solar powered UAV

With reference to mature technology of related technical field and the parameters of some products, the parameters of long-flight-time solar powered UAV which current domestic technology can realized are calculated, and some of the performance parameters are shown in table.1.

\section{TABLE I. TABLE TYPE STYLES}

\begin{tabular}{c|l|l}
\hline NO. & parameter & VALUE \\
\hline 1. & flight speed & $15 \mathrm{~m} / \mathrm{s} \quad(54 \mathrm{~km} / \mathrm{h})$ \\
\hline 2. & lift-drag ratio & $\mathrm{k}=35$ \\
\hline 3. & $\begin{array}{l}\text { Ratio of equipment electric power to } \\
\text { full-aircraft thrust power }\end{array}$ & $\mathrm{k}_{\mathrm{b}}=10 \%$ \\
\hline 4. & motor efficiency & $\eta_{m}=90 \%$ \\
\hline 5. & propeller efficiency & $\eta_{B}=80 \%$ \\
\hline 6. & storage battery energy density & $q=250 \mathrm{Wh} / \mathrm{kg}$ \\
\hline 7. & solar cell energy conversion efficiency & $\eta_{s}=16 \%$ \\
\hline 8. & solar energy density & $p_{s}=1000 \mathrm{~W} / \mathrm{m}^{2}$ \\
\hline 9. & weight per unit area of the solar cell & $q_{s}=0.5 \mathrm{~kg} / \mathrm{m}^{2}$ \\
\hline
\end{tabular}

By substituting the above performance parameters into (9), the weight of storage battery plus solar cell to whole machine weight ratio can be calculated:
$\left(Q_{b}+Q_{s}\right) / Q_{j}=\frac{v \times g \times\left(1+k_{b}\right)}{k \times \eta_{m} \times \eta_{B}} \times\left\{\frac{t}{q}+\frac{\left(\frac{t}{\eta_{c}}+24-t\right) \times \pi \times q_{s}}{p_{s} \times \eta_{s} \times(24-t)}\right\}=52 \%$

The calculation results show that the energy system weight of long-flight-time solar powered UAV reached more than half of the whole machine weight. In order to improve the task efficiency, there is the interacting relationship between the increase of airborne avionics equipment weight and the actual increased power consumption.

\section{CONCLUSION}

Long-flight-time solar powered UAV reflects the energy dynamic equilibrium process from collection, storage, management to consumption, which is one of the key factors of overall scheme and layout of long-flight-time solar powered UAV.

This method can effectively simplify the calculation process and provide a reference for the overall design of the long-flight-time solar powered UAV platform.

\section{REFERENCES}

[1] SHI Zhiguo. Advance of Power Supply for Military UAV [J]. Chinese Journal of Power Sources, 2012,5 (136) : 762-763.

[2] Cui Erjie. Research Statutes, Development Trends and Key Technical Problems of Near Space Flying Vehicles [J]. Advances In Mechanics, 2009,6 (39):658-672.

[3] Gao Guanglin. Key Technologies of Solar Powered Unmanned Air Vehicle [J]. Flight Dynamics, 2010,1 (28) :1-4.

[4] Deng Haiqiang, Yu Qiongqing. Solar Aircraft: Status and Directions [J]. Aeronautical Science And Technology, 2006,1:28-30.

[5] Chen Huaimin, Li Jingwen, Wang Peng. Design of Solar UAV Control Theory [J]. Computer Measurement \& Control.2011.19(9):2136-2139.

[6] Zheng Guo,et al. Development of a Solar Electric Powered UAV for Long-flight-time Flight [R]. AIAA-2011-6966, 2011

[7] William R. Hurd. Application of Copper Indium Gallium Diselenide Photovoltaic Cells to Extend the-flight-time and Capabilities of Unmanned Aerial Vehicles [R]. NASA Report, 2009.

[8] Hannes Ross. Fly around the World with a Solar Powered Airplane[R]. AIAA-2008-8954, 2008.

[9] Youngblood J W, Talay T A. Solar-powered airplane design for longendurance, high -altitude flight [R]. AIAA-1982 -0811, 1982.

[10] Obaid ur Rehman Alvi. Development of Solar Powered Aircraft for Multipurpose Application [R]. AIAA-2010-3061, 2010. 